\title{
Multiple-trait estimates of genetic parameters for metabolic disease traits, fertility disorders, and their predictors in Canadian Holsteins
}

\author{
J. Jamrozik, ${ }^{*}{ }^{1}$ A. Koeck, $\dagger$ G. J. Kistemaker, ${ }^{*}$ and F. Miglior ${ }^{*} \dagger$ \\ *Canadian Dairy Network, Guelph, Ontario, Canada, N1K 1E5 \\ †Centre for Genetic Improvement of Livestock, Department of Animal Biosciences, University of Guelph, Guelph, Ontario, Canada, N1G 2W1
}

\begin{abstract}
Producer-recorded health data for metabolic disease traits and fertility disorders on 35,575 Canadian Holstein cows were jointly analyzed with selected indicator traits. Metabolic diseases included clinical ketosis (KET) and displaced abomasum (DA); fertility disorders were metritis (MET) and retained placenta (RP); and disease indicators were fat-to-protein ratio, milk $\beta$-hydroxybutyrate, and body condition score (BCS) in the first lactation. Traits in first and later (up to fifth) lactations were treated as correlated in the multipletrait (13 traits in total) animal linear model. Bayesian methods with Gibbs sampling were implemented for the analysis. Estimates of heritability for disease incidence were low, up to 0.06 for DA in first lactation. Among disease traits, the environmental herd-year variance constituted $4 \%$ of the total variance for KET and less for other traits. First- and later-lactation disease traits were genetically correlated (from 0.66 to 0.72 ) across all traits, indicating different genetic backgrounds for first and later lactations. Genetic correlations between KET and DA were relatively strong and positive (up to 0.79 ) in both first- and later-lactation cows. Genetic correlations between fertility disorders were slightly lower. Metritis was strongly genetically correlated with both metabolic disease traits in the first lactation only. All other genetic correlations between metabolic and fertility diseases were statistically nonsignificant. First-lactation KET and MET were strongly positively correlated with later-lactation performance for these traits due to the environmental herd-year effect. Indicator traits were moderately genetically correlated (from 0.30 to 0.63 in absolute values) with both metabolic disease traits in the first lactation. Smaller and mostly nonsignificant genetic correlations were among indicators and metabolic diseases in later lactations. The only significant genetic correlations between indicators and fertility disorders were those between BCS and MET
\end{abstract}

Received October 9, 2015.

Accepted December 1, 2015.

${ }^{1}$ Corresponding author: jjamrozi@uoguelph.ca in both first and later lactations. Results indicated a limited value of a joint genetic evaluation model for metabolic disease traits and fertility disorders in Canadian Holsteins.

Key words: metabolic disease, fertility disorder, indicator trait, genetic parameter

\section{INTRODUCTION}

Breeding for disease resistance is becoming increasingly important for economic reasons as well as for animal welfare concerns and consumer demands for healthy and naturally produced food. In Canada, a national dairy cattle health data recording system started in 2007. Eight diseases that are known to affect herd profitability are recorded by producers (and veterinarians in Quebec) on a voluntary basis. Those diseases are clinical mastitis, displaced abomasum (DA), clinical ketosis (KET), milk fever, retained placenta (RP), metritis (MET), cystic ovaries, and lameness, as defined by Kelton et al. (1998). The feasibility of using producer-recorded health data from Canada for genetic evaluations has been shown previously by Neuenschwander (2010) and Koeck et al. (2012b), and the national genetic evaluation for resistance to clinical mastitis was implemented in August 2014 (Jamrozik et al., 2013; Miglior et al., 2014).

Genetic evaluation for metabolic disease traits has been considered the next step in utilizing health data collected on Canadian dairy farms for selection purposes. Two traits, KET and DA, were selected as specific metabolic disease traits based on our earlier studies (Koeck et al., 2015). Milk fever, as another disease with a metabolic background, has been found less suitable for classical genetic selection due to its very low frequency in first-parity cows, resulting in heritability of this trait in the first lactation being not different from zero. Fat to protein ratio $(\mathbf{F}: \mathbf{P}), \mathrm{BCS}$, and milk BHB were identified as indicator traits for metabolic diseases, given their relatively strong genetic correlations with KET and DA (Koeck et al., 2014a) and significantly higher heritabilities compared with the disease traits. Metritis, as a fertility disorder included in Canadian dairy health 
data collection, was shown to be genetically correlated with KET (0.32) and DA (0.44; Koeck et al., 2012b). Metritis was also highly genetically correlated with RP (0.62, Koeck et al., 2012b; 0.79, Neuenschwander et al., 2012). Genetic correlations between cystic ovaries and the other 2 fertility disorders (MET and RP) were small and statistically nonsignificant (Koeck et al., 2012b). Body condition score and F:P, as traits related to energy balance of the cow, can also be used as indicators for fertility disorders. Finally, BHB, as a trait correlated with metabolic diseases, may serve as well as a biomarker for fertility disorders. Metritis and RP were shown to have an effect on DA (LeBlanc et al., 2005) and thus could also be used as indicators for metabolic diseases. A multiple-trait model for KET, DA, MET, and RP, with F:P, BCS, and BHB as correlated (indicator) traits could therefore be considered for joint analysis of metabolic and fertility disease traits. Benefits would include greater accuracy of genetic evaluation through use of information from the correlated traits (Haugaard et al., 2015; Koeck et al., 2015) and no need for a development and running of 2 genetic evaluation systems, tailored separately for metabolic diseases and fertility disorder traits. Earlier studies with simpler models indicated that metabolic diseases as well as their indicators were genetically different traits in first- and later-lactation cows (Koeck et al., 2015). Treating first- and later-lactation disease traits as correlated in a multiple-trait model seems to be a proper strategy for genetic evaluation purposes.

The objective of this study was to estimate genetic parameters for KET, DA, MET, and RP, as well as their indicators (F:P, BCS, and $\mathrm{BHB}$ ) in the first and later lactations of Canadian Holsteins, using a multiple-trait animal model. This was the first attempt to analyze metabolic and fertility disease traits, along with their predictors, in one comprehensive model, in which performance in first and later lactations were treated as different but correlated traits.

\section{MATERIALS AND METHODS}

\section{Data}

The analyzed traits (13 traits in total) included

1. Metabolic disease traits from first and later (from 2 to 5) lactations: KET and DA. Both traits were scored as 0 (no case) or 1 (at least one case) in the period from calving to $100 \mathrm{~d}$ after calving. Days refer here (and for the other diseases) to the day of recording, not necessarily the day of treatment.
2. Fertility disorder traits from first and later lactations: RP and MET. Both trait were scored as 0 (no case) or 1 (at least one case) in the period from calving to $14 \mathrm{~d}(\mathrm{RP})$ or $150 \mathrm{~d}$ (MET) after calving.

3. Milk-recording predictor traits from first and later lactations: F:P at the first test-day (from 5 to 40 DIM), and BHB recorded between 5 and 40 DIM and $\log _{\mathrm{e}}(\mathrm{x}+1)$ transformed.

4. Conformation indicator trait: BCS from firstlactation cows; first classifications (reclassifications were not considered) within 305 DIM. This trait was routinely recorded by professional type classifiers on a scale from 1 (very thin) to 5 (very fat) in increments of 0.25 . Only first-lactation cows are routinely classified for BCS in Canada.

Health data recorded by dairy producers from April 2007 to December 2014, test-day records of F:P, and conformation records for BCS were provided by the Canadian Dairy Network (CDN; Guelph, ON, Canada). A minimum disease frequency (reported cases per herd and year) of $1 \%$ was applied for KET, DA, RP, and MET to ensure continuous data recording within individual herds. Test-day records for BHB were obtained from Valacta (Sainte-Anne-de-Bellevue, QC, Canada). Test-day milk samples were analyzed by a mid-infrared (MIR) spectrometer (MilkoScan FT+, Foss, Hillerød, Denmark) with previously developed calibration equations for milk BHB from Foss.

First- and later-lactation metabolic disease traits, fertility disorders, and milk-recording indicators were treated as different but correlated traits. Observations from lactations $>2$ were repeated records of lactation 2 . Edits included sequential edits on lactation number, all disease traits had to be recorded for a given lactation, and only lactations up to the fifth were retained.

This resulted in selection of the data on 35,575 cows with 52,996 lactation-specific records. Data for lactation 1 included 3,732 cows with health records but without BCS. Data on later lactations comprised 17,421 records. Descriptive statistics of the data are given in Table 1. Only $15 \%$ of first (19\% of later) lactations had BHB recorded. This was a consequence of the fact that screening for BHB in Canada started later compared with health data collection (October 2011) and it covered only Quebec and Atlantic provinces. Table 2 shows the distribution of the data by lactation number. There were 1,793 herd-year of calving classes in the data, and 65 levels for age at calving by season of calving. Four seasons of calving were defined as January to March, April to June, July to September, and October to December. Age at calving classes included 
Table 1. Descriptive statistics of the data used

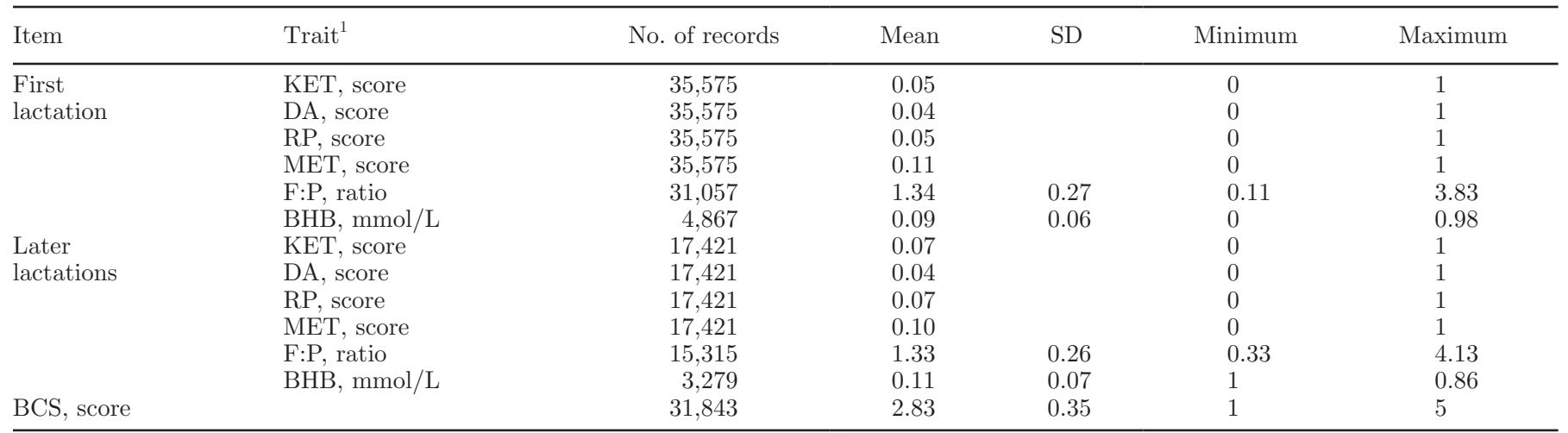

${ }^{1} \mathrm{KET}=$ ketosis, $\mathrm{DA}=$ displaced abomasum, $\mathrm{RP}=$ retained placenta, MET $=$ metritis, $\mathrm{F}: \mathrm{P}=$ fat-to-protein ratio.

8 levels for lactation $1(\leq 24,25,26,27,28,29,30-31$, $>31 \mathrm{mo}), 6$ levels for lactation $2(\leq 36,37,38,39-40$, $41-43,>43 \mathrm{mo}), 5$ levels for lactation $3(\leq 50,51-52$, $53-54,55-56,>56 \mathrm{mo}$ ), and 2 levels with thresholds of 63 and $75 \mathrm{mo}$ for lactations 4 and 5, respectively. For BCS, classes of round of classification, classifier, age at classification, stage of lactation at classification, and time period of classification were defined according to CDN standards (Loker et al., 2013), giving 3,649 and 160 levels for herd by round of classification and age at classification by stage of lactation at classification, respectively. Pedigree file associated with cows with phenotypes was tracked 7 generations back and included 157,933 animals.

\section{Models}

A multiple-trait animal linear model was applied for a simultaneous analysis of 13 traits. Single-trait models for individual traits were the same for KET, DA, RP, and MET, and for F:P and BHB. Example models for KET, F:P, and BCS in a simplified scalar notation (fixed effects are shown in uppercase letters) can be presented as

$$
\begin{gathered}
\mathrm{KET}=\mathrm{H}+\mathrm{YS}+\mathrm{AS}+\mathrm{hy}+\mathrm{a}+\mathrm{pe}+\mathrm{e}, \\
\mathrm{F}: \mathrm{P}=\mathrm{H}+\mathrm{YS}+\mathrm{AS}+\mathrm{hy}+\mathrm{a}+\mathrm{pe}+\mathrm{DIM}+\mathrm{e}, \\
\mathrm{BCS}=\mathrm{HRC}+\mathrm{AST}+\mathrm{a}+\mathrm{pe}+\mathrm{e},
\end{gathered}
$$

where the fixed effects were as follows: $\mathrm{H}=$ herd, YS = year by season, $\mathrm{AS}=$ age by season, $\mathrm{DIM}=$ days in milk, HRC = herd by round of classification by classifier, and AST = age at classification by stage of lactation at classification by time of classification, and the random effects were as follows: hy $=$ herd by year, $\mathrm{a}=$ animal additive genetic, pe $=$ permanent environmental
$(\mathbf{P E})$, and $\mathrm{e}=$ residual. In matrix notation, the model can be written as

$$
\mathbf{y}=\mathbf{X b}+\mathbf{Z}_{1} \mathbf{h}+\mathbf{Z}_{2} \mathbf{a}+\mathbf{Z}_{3} \mathbf{p}+\mathbf{e},
$$

where $\mathbf{y}$ is a vector of observations (traits within parities within cows), $\mathbf{b}$ is a vector of all fixed effects, $\mathbf{h}$ is a vector of hy effects, $\mathbf{a}$ is a vector of animal additive genetic effects (a), $\mathbf{p}$ is a vector of pe effects, $\mathbf{e}$ is a vector of residuals, and $\mathbf{X}$ and $\mathbf{Z}_{\mathrm{i}}(\mathrm{i}=1,2,3)$ are respective incidence matrices. Assumptions were that

$$
\left[\mathbf{h}^{\prime} \mathbf{a}^{\prime} \mathbf{p}^{\prime} \mathbf{e}^{\prime}\right]^{\prime} \sim N[\mathbf{0}, \mathbf{V}] \text { with } \mathbf{V}=\sum_{i=1}^{4}+\mathbf{V}_{i}
$$

where $\mathbf{V}_{1}=\mathbf{I} \otimes \mathbf{H}, \mathbf{I}$ is an identity matrix, $\mathbf{H}$ is a covariance $(12 \times 12)$ matrix for hy effects; $\mathbf{V}_{2}=\mathbf{A} \otimes \mathbf{G}$, $\mathbf{A}$ is an additive relationship matrix, $\mathbf{G}$ is a genetic covariance $(13 \times 13)$ matrix; $\mathbf{V}_{3}=\mathbf{I} \otimes \mathbf{P}, \mathbf{P}$ is a covariance $(13 \times 13)$ matrix for the pe effect; $\mathbf{V}_{4}=\sum_{i=1}^{N}{ }^{+} \mathbf{E}_{i}$, $\mathbf{E}_{i}$ is a residual covariance matrix (of order up to $7 \times 7$, depending on how many traits are missing for a given cow-parity combination) for either first or later lactations, $N$ is the total number of records, and $\sum^{+}$and $\otimes$ are direct sum and direct product operators, respectively. Residuals for diseases and milk recording indicator traits were assumed correlated within each lactation

Table 2. Distribution of records by lactation number

\begin{tabular}{lc}
\hline Lactation & No. of records \\
\hline 1 & 35,575 \\
2 & 11,943 \\
3 & 4,004 \\
4 & 1,183 \\
5 & 291 \\
\hline
\end{tabular}


and uncorrelated across lactation. All other residual correlations were equal to zero.

The multiple-trait model applied in this study can be considered as a meta-model combining 3 specific sub-models: (1) first-lactation disease traits and their indicators, (2) later-lactation disease traits and their indicators, and (3) BCS. If environmental co-variances among traits pertaining to different sub-models were not included (i.e., model residuals assumed to be independent), then those co-variances might enter genetic co-variances structure. As in Berry et al. (2003) and several other studies (e.g., Negussie et al., 2008a; Loker et al., 2012), within-animal environmental co-variance among traits belonging to the different sub-models was modeled by the PE effect. This effect allowed for a cowspecific, nonadditive genetic link between conformation data (BCS), health data, and milk-recording indicator traits. The PE co-variance estimates for single observation traits were later added to the residual components for these traits, leaving the specific PE parameters for repeated-measure traits only.

\section{Methods}

Bayesian methods with Gibbs sampling were used for fitting the model with the custom-written Fortran software. Prior distributions were normal for all location parameters, and inverted Wishart with minimal number of degrees of freedom for all dispersion parameters. The total length of the Gibbs chain was 250,000. Conservative burn-in period (50,000 iterations) was determined based on trace plots of selected covariance components. Estimates were calculated as posterior means of all samples after burn-in for respective parameters. The parameters were model covariance components, ratios of variances (including heritability), genetic, HY, PE, and residual correlations among respective traits. Posterior standard deviations were calculated as a measure of dispersion of estimated parameters. Statistical significance of point estimates (posterior mean) of parameters was determined by an approximate $95 \%$ Bayesian equal-tail credible interval; that is, by determining whether 0 was included in the interval: posterior mean $\pm 2 \times$ posterior $\mathrm{SD}$, for a given parameter.

\section{RESULTS}

Table 3 gives estimates (posterior means and SD) of phenotypic variance and ratios (\%) with respect to phenotypic variance for genetic $\left(h^{2}\right)$, herd-year $\left(h y^{2}\right)$, permanent environment $\left(\mathrm{pe}^{2}\right)$, and residual $\left(\mathrm{e}^{2}\right)$ variances. Residual variance for all first-lactation traits was expressed as a sum of PE and the model residual com- ponents. Estimates (posterior means $\times 100$ ) of genetic and PE correlations are in Table 4 . Table 5 presents estimates (posterior means $\times 100$ ) of herd-year correlations. Residual correlations for first- and later-lactation traits are in Table 6. As indicated earlier, residual correlations for the first lactation included the model co-variance components due to the PE effect. Similarly, $\mathrm{PE}$ correlations between first-lactation traits (including BCS) and later-lactation traits were equivalent to residual correlations among these traits.

\section{Variance Components}

Estimates of heritability for metabolic disease traits (Table 3) were from 0.02 (all disease traits in later lactations) to 0.06 (DA in first-lactation cows). Fertility disorders exhibited heritability of 0.02 across all traits and parities, with the exception of RP in first lactation (heritability of 0.03). Heritability of milk recording indicator traits ranged from 0.07 (BHB in later-lactation cows) to 0.16 (F:P in first lactation). Estimate of heritability for BCS was equal to 0.28.

Ketosis was the only disease trait with a significant contribution of the herd-year to the total (phenotypic) variance: 4.1 and $4.0 \%$ for the first and later parities, respectively. Permanent environmental effect captured around $3 \%$ of the total variance for all disease traits of later-lactation cows. Proportions of the within-cow environmental variance in later lactations were 7 and $25 \%$ for $\mathrm{F}: \mathrm{P}$ and $\mathrm{BHB}$, respectively.

\section{Genetic Correlations}

Genetic correlations between first and later lactations for the same disease trait were around 0.7 for all traits (Table 4). This indicated that disease resistance to metabolic and fertility disorders is a genetically different trait in first and later parities. Similar genetic correlation was estimated between $\mathrm{F}: \mathrm{P}$ in first and later parities. The corresponding estimate for BHB was 0.35.

Resistance to MET was genetically strongly correlated with resistance to KET (0.62) and DA (0.53) in the first lactation. Weaker and nonsignificant genetic correlations were estimated between RP and metabolic disease traits in the first parity. Genetic correlations between metabolic and fertility disease traits in laterlactation cows were low and mostly statistically insignificant.

Resistance to KET was genetically moderately correlated with the BHB level in the cow's milk, with correlations of 0.63 and 0.37 for first and later lactations, respectively. Weaker genetic relationships were estimated between DA and BHB in both first- and 
later-parity cows. Fat-to-protein ratio was a relatively good genetic indicator for metabolic trait diseases in first lactation. Genetic relationships between F:P and metabolic disease traits in later-parity cows and fertility disorders were weak and nonsignificant. Body condition score was a good genetic indicator of metabolic diseases and MET in the first lactation. Cows with high BCS in first lactation showed also better genetic resistance to MET in later parities.

\section{Environmental Correlations}

Most of the within-cow environmental correlations (PE) among disease traits and their indicators were statistically nonsignificant (Table 4). The exception was $\mathrm{F}: \mathrm{P}$ and $\mathrm{BHB}$ in later lactations. Correlations due to herd-year effect (Table 5) were positive and significant for KET, MET, and F:P in first and subsequent lactations. Residual correlations among traits in first lactation and in later parities were in general positive and significant (Table 6). Correlations due to the PE effects among BCS and other first lactation traits (equivalent to residual correlations for this group of traits) ranged from -0.34 (0.11) for F:P to 0.18 (0.12) for RP.

\section{DISCUSSION}

Linear models were fitted for disease resistance binary traits in this study. A binary model based on the threshold concept would be, at least theoretically, more suitable, but linear approximation has been proven in many applications to work relatively well. Neuenschwander et al. (2012), in the earlier study on Canadian dairy health data, showed that use of the threshold model did not improve the goodness of fit compared with the linear model. Similar results were obtained in other studies (e.g., Negussie et al., 2008b). Estimates of heritability are usually higher when threshold model methodology is applied, but genetic correlations are reported to be correct for binary traits using linear models (Heringstad et al., 2005; Negussie et al., 2008b). Linear models are also usually used for routine genetic evaluation of binary variables, including disease resistance traits (e.g., Jamrozik et al., 2013).

\section{Heritabilities}

Estimates of heritability for disease traits and their indicators were in good agreement with our previous

Table 3. Estimates (posterior means) of phenotypic variance and ratios (\%) with respect to phenotypic variance for genetic $\left(\mathrm{h}^{2}\right)$, herd-year $\left(\mathrm{hy}^{2}\right)$, permanent environment $\left(\mathrm{pe}^{2}\right)$, and residual $\left(\mathrm{e}^{2}\right)$ variances (posterior $\mathrm{SD}$ in parentheses)

\begin{tabular}{|c|c|c|c|c|c|c|}
\hline Lactation & Trait $^{1}$ & $\begin{array}{c}\text { Total } \\
\text { variance }\end{array}$ & $h^{2}$ & $\mathrm{hy}^{2}$ & $\mathrm{pe}^{2}$ & $e^{2}$ \\
\hline \multirow[t]{8}{*}{ First } & KET & $\begin{array}{c}0.042 \\
(0.0003)\end{array}$ & $\begin{array}{l}3.77 \\
(0.726)\end{array}$ & $\begin{array}{l}4.12 \\
(0.280)\end{array}$ & & $\begin{array}{l}92.11 \\
(0.769)\end{array}$ \\
\hline & $\mathrm{DA}$ & $\begin{array}{c}0.035 \\
(0.0003)\end{array}$ & $\begin{array}{l}6.36 \\
(0.809)\end{array}$ & 0.39 & & 93.25 \\
\hline & $\mathrm{RP}$ & $\begin{array}{l}0.047 \\
(0.0004)\end{array}$ & $\begin{array}{l}2.73 \\
(0.560)\end{array}$ & $\begin{array}{c}0.45 \\
(0.082)\end{array}$ & & $\begin{array}{l}96.83 \\
(0.565)\end{array}$ \\
\hline & MET & 0.091 & 1.89 & 0.78 & & 97.33 \\
\hline & & $(0.0007)$ & $(0.422)$ & $(0.162)$ & & $(0.450)$ \\
\hline & $\mathrm{F}: \mathrm{P}$ & $\begin{array}{c}0.062 \\
(0.0006)\end{array}$ & $\begin{array}{l}16.36 \\
(1.813)\end{array}$ & $\begin{array}{l}2.04 \\
(0.225)\end{array}$ & & $\begin{array}{l}81.60 \\
(1.830)\end{array}$ \\
\hline & BHB & 0.004 & 12.68 & 1.18 & & 86.14 \\
\hline & & $(0.0001)$ & $(2.513)$ & $(0.243)$ & & $(2.522)$ \\
\hline \multirow[t]{11}{*}{ Later } & KET & 0.060 & 2.26 & 3.99 & 3.53 & 90.22 \\
\hline & $\mathrm{DA}$ & 0.039 & $\begin{array}{c}(0.437) \\
219\end{array}$ & $\begin{array}{c}(0.394) \\
0.40\end{array}$ & $\begin{array}{c}(0.614) \\
2.98\end{array}$ & $\begin{array}{l}(0.812) \\
94.42\end{array}$ \\
\hline & & $(0.0004)$ & $(0.341)$ & $(0.095)$ & $(0.452)$ & $(0.572)$ \\
\hline & $\mathrm{RP}$ & 0.064 & 2.20 & 0.36 & 2.92 & 94.51 \\
\hline & & $(0.0007)$ & $(0.497)$ & $(0.084)$ & $(0.537)$ & $(0.703)$ \\
\hline & MET & 0.086 & 1.77 & 0.42 & 3.71 & 94.10 \\
\hline & & $(0.0009)$ & $(0.332)$ & $(0.114)$ & $(0.731)$ & $(0.800)$ \\
\hline & $\mathrm{F}: \mathrm{P}$ & 0.062 & 9.73 & 2.78 & 7.21 & 80.28 \\
\hline & & $(0.0007)$ & (1.192) & $(0.326)$ & (1.097) & (1.110) \\
\hline & BHB & 0.005 & 6.72 & 2.59 & 25.41 & 65.28 \\
\hline & & $(0.0001)$ & $(2.147)$ & $(0.607)$ & $(2.251)$ & $(2.219)$ \\
\hline \multirow[t]{2}{*}{ BCS } & & 0.094 & 28.23 & & & 71.77 \\
\hline & & $(0.0010)$ & $(2.101)$ & & & $(2.101)$ \\
\hline
\end{tabular}

${ }^{1} \mathrm{KET}=$ ketosis, $\mathrm{DA}=$ displaced abomasum, $\mathrm{RP}=$ retained placenta, $\mathrm{MET}=$ metritis, $\mathrm{F}: \mathrm{P}=$ fat-to-protein ratio. 
Table 4. Estimates (posterior means $\times 100$ ) of genetic correlations (above diagonal) and permanent environmental correlations (below diagonal) (posterior SD in parentheses)

\begin{tabular}{|c|c|c|c|c|c|c|c|c|c|c|c|c|c|c|}
\hline \multirow{2}{*}{\multicolumn{2}{|c|}{ Lactation/trait ${ }^{1}$}} & \multicolumn{6}{|c|}{ First } & \multicolumn{6}{|c|}{ Later } & \multirow[b]{2}{*}{ BCS } \\
\hline & & KET & DA & $\mathrm{RP}$ & MET & $\mathrm{F}: \mathrm{P}$ & $\begin{array}{l}\text { BH } \\
\text { BA }\end{array}$ & KET & DA & $\mathrm{RP}$ & MET & $F: P$ & $\begin{array}{l}\mathrm{BH} \\
\mathrm{BA}\end{array}$ & \\
\hline \multirow[t]{7}{*}{ First } & KET & & $\begin{array}{l}79 \\
(4)\end{array}$ & $\begin{array}{c}21 \\
(15)\end{array}$ & $\begin{array}{c}62 \\
(10)\end{array}$ & $\begin{array}{l}41 \\
(9)\end{array}$ & $\begin{array}{c}63 \\
(9)\end{array}$ & $\begin{array}{c}66 \\
(10)\end{array}$ & $\begin{array}{l}58 \\
(9)\end{array}$ & $\begin{array}{c}9 \\
(16)\end{array}$ & $\begin{array}{c}42 \\
(15)\end{array}$ & $\begin{array}{c}7 \\
(11)\end{array}$ & $\begin{array}{c}25 \\
(14)\end{array}$ & $\begin{array}{r}-56 \\
\quad(6)\end{array}$ \\
\hline & $\mathrm{DA}$ & & & $\begin{array}{c}16 \\
(14)\end{array}$ & $\begin{array}{c}53 \\
(10)\end{array}$ & $\begin{array}{l}30 \\
(9)\end{array}$ & $\begin{array}{c}36 \\
(10)\end{array}$ & $\begin{array}{c}58 \\
(10)\end{array}$ & 72 & $\begin{array}{c}7 \\
(13)\end{array}$ & $\begin{array}{c}37 \\
(16)\end{array}$ & $\begin{array}{c}5 \\
5\end{array}$ & $\begin{array}{c}5 \\
5\end{array}$ & -41 \\
\hline & MET & & & & & $\begin{array}{c}29 \\
(11)\end{array}$ & $\begin{array}{c}37 \\
(13)\end{array}$ & $\begin{array}{c}26 \\
(17)\end{array}$ & $\begin{array}{c}35 \\
(12)\end{array}$ & $\begin{array}{c}48 \\
(11)\end{array}$ & $\begin{array}{l}66 \\
(8)\end{array}$ & $\begin{array}{c}4 \\
(12)\end{array}$ & $\begin{array}{c}9 \\
(15)\end{array}$ & $\begin{array}{r}-43 \\
(8)\end{array}$ \\
\hline & $F: P$ & & & & & & 49 & 30 & 10 & -2 & 19 & 70 & 15 & -38 \\
\hline & & & & & & & (9) & $(13)$ & (12) & (14) & (11) & $(5)$ & $(11)$ & $(6)$ \\
\hline & BHB & & & & & & & 41 & 7 & 3 & 22 & 12 & 35 & -63 \\
\hline & & & & & & & & $(15)$ & (14) & (18) & (14) & (12) & (14) & (6) \\
\hline \multirow[t]{8}{*}{ Later } & KET & 8 & -15 & -8 & 11 & 3 & 7 & & 55 & -14 & 6 & 19 & 37 & -19 \\
\hline & & (13) & (12) & (11) & (14) & (11) & (11) & (15) & (12) & & (13) & (14) & (19) & (10) \\
\hline & MET & -1 & -23 & -7 & 33 & -7 & 8 & 9 & 23 & 19 & & -9 & -14 & -47 \\
\hline & & (12) & (11) & (11) & (12) & (10) & (9) & (14) & (11) & (14) & & (12) & (14) & (10) \\
\hline & $F: P$ & -1 & -4 & -9 & 13 & 27 & 15 & 7 & 16 & 0 & 13 & & 20 & 9 \\
\hline & & (10) & (9) & (9) & (12) & (8) & (8) & (11) & (10) & (13) & (11) & & (15) & (7) \\
\hline & BHB & 9 & -3 & -3 & 7 & 10 & 21 & 8 & 8 & 2 & 11 & 25 & & 4 \\
\hline & & (8) & $(8)$ & $(8)$ & (9) & $(7)$ & (6) & (9) & (8) & (9) & (9) & (8) & & (12) \\
\hline \multirow{2}{*}{\multicolumn{2}{|c|}{ BCS }} & -9 & -7 & 18 & 7 & -34 & -18 & -3 & 5 & 10 & 20 & 5 & 3 & \\
\hline & & (13) & (12) & (12) & (15) & (11) & (9) & (13) & (12) & (14) & (14) & (12) & (9) & \\
\hline
\end{tabular}

${ }^{1} \mathrm{KET}=$ ketosis, $\mathrm{DA}=$ displaced abomasum, $\mathrm{RP}=$ retained placenta, $\mathrm{MET}=$ metritis, $\mathrm{F}: \mathrm{P}=$ fat-to-protein ratio.

Table 5. Estimates (posterior means $\times 100$ ) of herd-year correlations (posterior SD in parentheses)

\begin{tabular}{|c|c|c|c|c|c|c|c|c|c|c|c|c|c|}
\hline \multicolumn{2}{|c|}{ Lactation/trait ${ }^{1}$} & \multicolumn{6}{|c|}{ First } & \multicolumn{6}{|c|}{ Later } \\
\hline Later & $\begin{array}{l}\text { KET } \\
\text { DA } \\
\text { RP } \\
\text { MET } \\
\text { F:P } \\
\text { BHB } \\
\text { KET } \\
\text { DA } \\
\text { RP } \\
\text { MET } \\
\text { F:P } \\
\text { BHB }\end{array}$ & & $\begin{array}{l}-3 \\
(10)\end{array}$ & $\begin{array}{c}-1 \\
(10) \\
12 \\
(12)\end{array}$ & $\begin{array}{c}-4 \\
(8) \\
18 \\
(13) \\
30 \\
(13)\end{array}$ & $\begin{array}{c}1 \\
(6) \\
16 \\
(11) \\
4 \\
(11) \\
10 \\
(10)\end{array}$ & $\begin{array}{c}1 \\
(18) \\
7 \\
(12) \\
-4 \\
(13) \\
3 \\
(15) \\
38 \\
(11)\end{array}$ & $\begin{array}{c}88 \\
(3) \\
-7 \\
(11) \\
4 \\
(11) \\
-7 \\
(10) \\
-7 \\
(7) \\
-5 \\
(18)\end{array}$ & $\begin{array}{c}32 \\
(14) \\
-3 \\
(13) \\
-5 \\
(14) \\
-10 \\
(18) \\
0 \\
(13) \\
1 \\
(14) \\
35 \\
(13)\end{array}$ & $\begin{array}{c}5 \\
(15) \\
7 \\
(14) \\
12 \\
(14) \\
16 \\
(17) \\
17 \\
(13) \\
9 \\
(14) \\
1 \\
(15) \\
2 \\
(16)\end{array}$ & $\begin{array}{c}-6 \\
(14) \\
14 \\
(14) \\
20 \\
(14) \\
46 \\
(14) \\
1 \\
(13) \\
-3 \\
(15) \\
-7 \\
(14) \\
-12 \\
(17) \\
14 \\
(17)\end{array}$ & $\begin{array}{c}1 \\
(8) \\
9 \\
(12) \\
-1 \\
(12) \\
9 \\
(12) \\
47 \\
(7) \\
30 \\
(13) \\
-1 \\
(8) \\
6 \\
(13) \\
9 \\
(13) \\
0 \\
(13)\end{array}$ & $\begin{array}{c}-20 \\
(20) \\
2 \\
(14) \\
-7 \\
(14) \\
0 \\
(18) \\
22 \\
(13) \\
25 \\
(14) \\
-22 \\
(20) \\
-3 \\
(16) \\
4 \\
(16) \\
-5 \\
(17) \\
37 \\
(13)\end{array}$ \\
\hline
\end{tabular}

${ }^{1} \mathrm{KET}=$ ketosis, $\mathrm{DA}=$ displaced abomasum, $\mathrm{RP}=$ retained placenta, $\mathrm{MET}=$ metritis, $\mathrm{F}: \mathrm{P}=$ fat-to-protein ratio. 
estimates from simpler linear models (Koeck et al., 2015) and earlier studies of Koeck et al. (2012b) and Neuenschwander et al. (2012) that also used producerrecorded Canadian Holstein data. Heritability estimates were generally low but comparable with results from studies using data from other populations. For KET, Simianer et al. (1991) reported heritability of 0.08 on the underlying scale, and Kadarmideen et al. (2000) estimated heritability of 0.02 and 0.01 from threshold and linear models, respectively. Higher estimates were obtained by Heringstad et al. (2005) with a threshold model: $0.14,0.15$, and 0.16 for first, second, and third lactations, respectively. Estimates of heritability for DA with the threshold model were between 0.09 and 0.28 (Uribe et al., 1995; Abdel-Azim et al., 2005). Zwald et al. (2004a) reported heritability of DA on the underlying scale equal to 0.18 and 0.15 for first and all lactations, respectively. No genetic effects for DA was found by Van Dorp et al. (1998) using Canadian data and the linear model. Lin et al. (1989) estimated heritability of 0.05 and 0.09 on the linear scale for RP in first and second lactation, respectively, whereas estimates of Distl et al. (1991) for the same trait and the first 3 lactations were 0.01, 0.01, and 0.02. Estimates of Heringstad et al. (2005) for RP in lactations 1 to 3 on the underlying scale were the same (0.08). Estimates of heritability for MET differed more between studies with linear models, from 0.05 (Mäntysaari et al., 1993) to 0.26 (Lin et al., 1989). It has to be emphasized, however, that linear model estimates of heritability for binary traits are frequency dependent, and therefore, not directly comparable. Recently, Haugaard and Heringstad (2015) reported heritability on the underlying scale in lactations from 1 to 5 of Norwegian Red cattle between 0.04 and 0.06 , and between 0.06 and 0.09 , for MET and RP, respectively.

Table 6. Estimates (posterior means $\times 100$ ) of residual correlations for first lactation (above diagonal) and later lactation (below diagonal) traits (posterior SD in parentheses)

\begin{tabular}{lcccccc}
\hline Trait $^{1}$ & KET & DA & RP & MET & F:P & BHB \\
\hline KET & & 21 & 2 & 4 & 8 & 16 \\
DA & 26 & $(1)$ & $(1)$ & $(1)$ & $(1)$ & $(2)$ \\
& $(1)$ & & 3 & 4 & 7 & 3 \\
RP & 2 & 4 & $(1)$ & $(1)$ & $(1)$ & $(2)$ \\
& $(1)$ & $(1)$ & & 15 & -1 & -2 \\
MET & 2 & 3 & 25 & $(1)$ & $(1)$ & $(2)$ \\
& $(1)$ & $(1)$ & $(1)$ & & 1 & 0 \\
F:P & 11 & 14 & -1 & 1 & $(1)$ & $(1)$ \\
& $(1)$ & $(1)$ & $(1)$ & $(1)$ & & 49 \\
BHB & 22 & 9 & -1 & 1 & 54 & $(2)$ \\
& $(2)$ & $(2)$ & $(2)$ & $(2)$ & $(2)$ &
\end{tabular}

${ }^{1} \mathrm{KET}=$ ketosis, $\mathrm{DA}=$ displaced abomasum, $\mathrm{RP}=$ retained placenta, $\mathrm{MET}=$ metritis, $\mathrm{F}: \mathrm{P}=$ fat-to-protein ratio.

\section{Genetic Correlations}

Estimates of genetic and environmental correlations among disease trait or between lactations for the same trait are less frequent in the literature. Usually, single-trait models have been employed and the data comprised either first or all lactations. Genetic correlations between KET in different lactations were between 0.78 and 0.86 in Heringstad et al. (2005), and they concluded that KET could be considered the same trait in the first 3 lactations. The same authors reported genetic correlations between RP in lactations 1 to 3 between 0.55 and 0.65 , indicating a different genetic background for this trait across lactations. Estimates of genetic correlation between first and later lactations by Koeck et al. (2015) using producer-recorded Canadian Holstein data were slightly higher than results obtained in the current study: 0.79 for KET and 0.86 for DA. Genetic correlation between KET and DA in the first lactation was higher than earlier estimates of Koeck et al. (2012b) with the same data (0.64). The correlation between metabolic disease traits in later lactation was smaller and comparable with estimates of Zwald et al. (2004b) and Neuenschwander et al. (2012). Retained placenta and MET had the same correlations between lactations (0.6) that were similar to estimates of Koeck et al. (2012b) for the first lactation but smaller than results of Neuenschwander et al. (2012), Lin et al. (1989) and Heringstad (2010). Haugaard and Heringstad (2015) reported higher genetic correlations between lactations (from 1 to 5) in Norwegian Red cattle. Their liability scale estimates ranged from 0.71 to 0.87 for MET, and from 0.84 to 0.93 for RP. In the first lactation, KET and DA were moderately correlated with MET, and genetically unrelated to RP in the study of Koeck et al. (2012b), which was in agreement with the current study. Relationships between metabolic disease traits and fertility disorders could not be confirmed, however, for cows in later lactations. Haugaard and Heringstad (2015) reported correlations between lactations (from 1 to 5) for MET and RP.

\section{Relationships Between Diseases and Indicator Traits}

Genetic associations among disease traits and their indicators confirmed earlier results of Koeck et al. (2012a, 2013, 2014a) and Loker et al. (2012). Milk BHB and $\mathrm{F}: \mathrm{P}$ were relatively good indicators for metabolic diseases in the first lactation. Later lactations were characterized by weaker links between KET and DA with their milk-recording predictors. Similar relationships were exhibited for BCS as an indicator for metabolic diseases. Fat-to-protein ratio and milk BHB are used as indicators for indirectly establishing KET in 
dairy cows in the Netherlands. Routine evaluation for KET using such indicators as phenotypes for ketosis has been recently implemented in the Netherlands (Vosman et al., 2015).

A different pattern was noticed for $\mathrm{F}: \mathrm{P}, \mathrm{BHB}$, and BCS as indicator for fertility disorders. The only significant relationship was between BCS and MET in both first and later lactations. Fat-to-protein ratio and BHB did not exhibit any potential as predictors for fertility disorders in the current study. LeBlanc et al. (2005) indicated that MET and RP have an effect on DA. Only MET in the first lactation was shown to have moderate genetic relationships with metabolic disease in this study. Given the very low heritability for MET, the value of this trait as an indicator for resistance to metabolic diseases seems to be of limited value.

\section{Genetic Evaluation Issues}

Canada is planning to introduce a routine genetic evaluation for metabolic disease traits (KET and DA) in the near future, followed by a similar procedure for fertility disorders (RP and MET). Results of this study indicate that genetic evaluation for resistance to metabolic diseases and fertility disorders should be done in separate (uncorrelated) systems. For metabolic disease traits, first and later lactations should be considered as different (but correlated) traits; and F:P, BHB, and BCS should be used as indicator traits in the multipletrait model to increase the accuracy of genetic evaluation (Koeck et al., 2015). Genetic evaluation for fertility disorders should follow, in general, a similar strategy, but only BCS should be used as indicator for this group of traits. There is a possibility to use other traits as biomarkers for RP and MET. Calving difficulty, weight of the calf, multiple births, stillbirths, and abortions were shown to have an effect on RP (Joosten et al., 1987; Koeck et al., 2014b). Abnormal calvings (dystocia) are also a risk factor for MET (Benzaquen et al., 2007). More research is needed in this area.

\section{CONCLUSIONS}

Resistance to metabolic diseases and fertility disorders were shown to be heritable and genetically different traits in first and later lactations of Canadian Holstein cows. Ketosis and DA, as well as RP and MET, were pair-wise genetically correlated, whereas MET and both metabolic disease traits in the first lactation only showed significant genetic correlation. Fat-to-protein ratio, milk BHB, and BCS were relatively good indicators of metabolic disease traits in the first lactation and, to a lesser degree, in later lactations. Only BCS showed reasonably good genetic predictive properties for MET across all lactations. Fertility disorders had a limited value as indicators in genetic evaluation for MET and DA resistance in Canadian Holsteins.

\section{ACKNOWLEDGMENTS}

All dairy producers recording health data are gratefully acknowledged. The study was funded by DairyGen Council (Guelph) and NSERC (Ottawa), Dairy Research Cluster Initiative [Dairy Farmers of Canada (Ottawa), Agriculture and Agri-Food Canada (Ottawa), the Canadian Dairy Network (Guelph), and the Canadian Dairy Commission (Ottawa)] and Ontario Genomics Institute (Toronto).

\section{REFERENCES}

Abdel-Azim, G. A., A. E. Freeman, M. E. Kegrli Jr., S. C. Kelm, J. L. Burton, A. L. Kuck, and S. Schnell. 2005. Genetic basis and risk factors for infectious and noninfectious diseases in US Holstein. I. Estimation of genetic parameters for single diseases and general health. J. Dairy Sci. 88:1199-1207.

Benzaquen, M. E., C. A. Risco, L. F. Archibald, P. Melendez, M.-J. Thatcher, and W. W. Thatcher. 2007. Rectal temperature, calving-related factors, and the incidence of puerperal metritis in postpartum dairy cows. J. Dairy Sci. 90:2804-2814.

Berry, D. P., F. Buckley, P. Dillon, R. D. Evans, M. Rath, and R. F. Veerkamp. 2003. Genetic parameters for body condition score, body weight, milk yield, and fertility estimated using random regression models. J. Dairy Sci. 86:3704-3717.

Distl, O., M. Ron, G. Francos, E. Mayer, and H. Kraeusslich. 1991. Genetic analysis of reproductive disorders in Israeli Holstein dairy cows. Theriogenology 35:827-836.

Haugaard, K., and B. Heringstad. 2015. Short communication: Genetic parameters for fertility-related disorders in Norwegian Red. J. Dairy Sci. 98:1321-1324.

Haugaard, K., M. Svendsen, and B. Heringstad. 2015. Information from later lactations improve accuracy of genomic predictions of fertility-related disorders in Norwegian Red. J. Dairy Sci. 98:49284933.

Heringstad, B. 2010. Genetic analysis of fertility-related diseases and disorders in Norwegian Red cows. J. Dairy Sci. 93:2751-2756.

Heringstad, B., Y. M. Chang, D. Gianola, and G. Klemetsdal. 2005. Genetic analysis of clinical mastitis, milk fever, ketosis, and retained placenta in three lactations of Norwegian Red cows. J. Dairy Sci. 88:3273-3281.

Jamrozik, J., A. Koeck, F. Miglior, G. Kistemaker, F. Schenkel, D Kelton, and B. Van Doormaal. 2013. Genetic and genomic evaluation of mastitis resistance in Canada. Interbull Bull. 47:43-51.

Joosten, I., P. van Eldik, L. Elving, and G. J. W. van der Mey. 1987. Factors related to the etiology of retained placenta in dairy cattle. Anim. Reprod. Sci. 14:251-262.

Kadarmideen, H. N., R. Thompson, and G. Simm. 2000. Linear and threshold model genetic parameters for disease, fertility and milk production in dairy cattle. Anim. Sci. 81:411-419.

Kelton, D. F., K. D. Lissemore, and R. E. Martin. 1998. Recommendations for recording and calculating the incidence of selected clinical diseases of dairy cattle. J. Dairy Sci. 81:2502-2509.

Koeck, A., J. Jamrozik, G. J. Kistemaker, F. S. Schenkel, R. K. Moore, D. M. Lefebvre, D. F. Kelton, and F. Miglior. 2015. Development of genetic evaluations for metabolic disease traits for Canadian dairy cattle. Interbull Bull. 49:76-79.

Koeck, A., J. Jamrozik, F. S. Schenkel, R. K. Moore, D. M. Lefebvre, D. F. Kelton, and F. Miglior. 2014a. Genetic analysis of milk $\beta$-hydroxybutyrate and its association with fat to protein ratio, body condition score, clinical ketosis and displaced abomasum in 
early first lactation Canadian Holsteins. J. Dairy Sci. 97:72867292.

Koeck, A., F. Miglior, J. Jamrozik, D. F. Kelton, and F. S. Schenkel. 2013. Genetic associations of ketosis and displaced abomasum with milk production traits in early first lactation of Canadian Holsteins. J. Dairy Sci. 96:4688-4696.

Koeck, A., F. Miglior, J. Jamrozik, D. F. Kelton, and F. S. Schenkel. 2014b. Genetic relationships of fertility disorders with reproductive traits in Canadian Holsteins. Commun. 153 in Proc. 10th WCGALP, Vancouver, Canada. Am. Soc. Anim. Sci., Champaign, IL.

Koeck, A., F. Miglior, D. F. Kelton, and F. S. Schenkel. 2012a. Short communication: Genetic association of body condition score with disease resistance in first lactation Canadian Holsteins. Can. J. Anim. Sci. 92:285-289.

Koeck, A., F. Miglior, D. F. Kelton, and F. S. Schenkel. 2012b. Health recording in Canadian Holsteins: Data and genetic parameters. J. Dairy Sci. 95:4099-4108.

LeBlanc, S. J., K. E. Leslie, and T. F. Duffield. 2005. Metabolic predictors of displaced abomasum in dairy cattle. J. Dairy Sci. 88:159-170.

Lin, H. K., P. A. Oltenacu, L. D. Van Vleck, H. N. Erb, and R. D. Smith. 1989. Heritabilities of and genetic correlations among six health problems in Holstein cows. J. Dairy Sci. 72:180-186.

Loker, S., C. Bastin, F. Miglior, A. Sewalem, L. R. Schaeffer, J. Jamrozik, V. Osborne, and A. Ali. 2013. Development of a genetic evaluation for body condition score for Canadian Holsteins. J. Dairy Sci. 96:3994-4004.

Loker, S., F. Miglior, A. Koeck, T. F. Neuenschwander, C. Bastin, J. Jamrozik, L. R. Schaeffer, and D. Kelton. 2012. Relationships between body condition score and health traits in first-lactation Canadian Holsteins. J. Dairy Sci. 95:6770-6780.

Mäntysaari, E. A., Y. T. Gröhn, and R. L. Quaas. 1993. Repeatability and heritability of lactational occurrence of reproductive disorders in dairy cows. Prev. Vet. Med. 17:111-125.

Miglior, F., A. Koeck, J. Jamrozik, F. S. Schenkel, D. F. Kelton, G. J. Kistemaker, and B. J. Van Doormaal. 2014. Index for mastitis resistance and use of BHBA for evaluation of health traits in $\mathrm{Ca}-$ nadian Holsteins. Interbull Bull. 48:73-78.
Negussie, E., I. Strandén, and E. A. Mäntysaari. 2008a. Genetic association of clinical mastitis with test-day somatic cell score and milk yield during first lactation of Finnish Ayrshire cows. J. Dairy Sci. 91:1189-1197.

Negussie, E., I. Strandén, and E. A. Mäntysaari. 2008b. Genetic analysis of liability to clinical mastitis, with somatic cell score and production traits using bivariate threshold-linear and linear-linear models. Livest. Sci. 117:52-59.

Neuenschwander, T. F.-O. 2010. Studies on disease resistance based on producer-recorded data in Canadian Holsteins. PhD Thesis. University of Guelph, Guelph, ON, Canada.

Neuenschwander, T. F.-O., F. Miglior, J. Jamrozik, O. Berke, D. F. Kelton, and L. R. Schaeffer. 2012. Genetic parameters for producer-recorded health data in Canadian Holstein cattle. Animal 6:571-578

Simianer, H., H. Solbu, and L. R. Schaeffer. 1991. Estimated genetic correlations between disease and yield traits in dairy cattle. J. Dairy Sci. 74:4358-4365

Uribe, H. A., B. W. Kennedy, S. W. Martin, and D. F. Kelton. 1995. Genetic parameters for common health disorders of Holstein cows. J. Dairy Sci. 78:421-430.

Van Dorp, T. E., J. C. M. Dekkers, S. W. Martin, and J. P. Noordhuizen. 1998. Genetic parameters of health disorders, and relationships with 305-day milk yield and conformation traits of registered Holstein cows. J. Dairy Sci. 81:2264-2270.

Vosman, J. J., G. de Jong, H. Eding, and H. Knijn. 2015. Genetic evaluation for ketosis in the Netherlands based on FTIR measurements. Interbull Bull. 49:1-5.

Zwald, N. R., K. A. Weigel, Y. M. Chang, R. D. Welper, and J. S. Clay. 2004a. Genetic selection for health using producer-recorded data. I. Incidence rates, heritability estimates, and sire breeding values. J. Dairy Sci. 87:4287-4294

Zwald, N. R., K. A. Weigel, Y. M. Chang, R. D. Welper, and J. S. Clay. 2004b. Genetic selection for health using producer-recorded data. II. Genetic correlations, disease probabilities and relationships with existing traits. J. Dairy Sci. 87:4295-4302. 